\title{
Influence of Arctic Oscillation on Frequency of Wintertime Fog Days in Eastern China
}

\author{
Peng Liu ${ }^{1} * \mathbb{D}$, Mingyue Tang ${ }^{2}$, Huaying $\mathrm{Yu}^{1}$ and Ying Zhang ${ }^{1}$ \\ 1 Key Laboratory of Meteorological Disaster, Ministry of Education (KLME)/Joint International Research \\ Laboratory of Climate and Environmental Change (ILCEC)/Collaborative Innovation Center on Forecast and \\ Evaluation of Meteorological Disasters (CIC-FEMD), Nanjing University of Information Science and \\ Technology, Nanjing 210044, China; yhylp@nuist.edu.cn (H.Y.); 15951618319@163.com (Y.Z.) \\ 2 School of Ocean and Earth Science and Technology, University of Hawaii, Honolulu, HI 96822, USA; \\ mingyue@hawaii.edu \\ * Correspondence: liupeng1998@nuist.edu.cn
}

Received: 11 December 2019; Accepted: 28 January 2020; Published: 4 February 2020

\begin{abstract}
The influence of Arctic Oscillation (AO) on the frequency of wintertime fog days in eastern China is studied based on the winter AO index, the wintertime fog-day data of national stations in China, and the National Centers for Environmental Prediction/National Center for Atmospheric Research (NCEP/NCAR) reanalysis data from 1954 to 2007. The results show that heavy fog and light fog are more likely to occur during winter in eastern China with the strong interannual variability. During the winter with the positive-phase AO, there are more days of heavy fog in North China but less in South China, while light fog days become more in the whole of eastern China. It is mainly because that when $\mathrm{AO}$ is in the positive phase, the pressure in the polar region decreases at $500 \mathrm{hPa}$; the pressure in East Asia increases anomalously; the East Asian trough decreases; and the low-level westerly jet moves northward, preventing the northwesterly cold air from moving southward. Therefore, the whole eastern China gets warmer and wetter air, and there are more light fog days with the enhanced water vapor. However, the atmosphere merely becomes more towards unstable in South China, where the precipitation increases but the heavy fog days decreases. Nevertheless, heavy fog days increase with the water vapor in North China because of moving towards a stable atmosphere, which is formed by the anomalous downdrafts north of the precipitation center in South China. When AO is in the negative phase, the situation is basically opposite to that in the positive phase, but the variations of the corresponding fog days and circulations are weaker than those in the AO-positive-phase winter, which may be related to the nonlinear effect of $\mathrm{AO}$ on climate.
\end{abstract}

Keywords: arctic oscillation (AO); fog days; eastern China

\section{Introduction}

In recent years, the fog and haze have occurred frequently in China, affecting the traffic and economic development. The large number of harmful substances in the fog or haze can affect people's health and bring great harm [1]. Fog is defined as a weather phenomenon with the effective visibility of less than $1 \mathrm{~km}$ and the relative humidity greater than $90 \%$ or close to $100 \%$. The formation of fog is relatively complex. Fog as a research project can be divided into different tempo-spatial scales to study, for example on ice fog, marine fog, fog microphysics, fog climate change and so on [2-6]. In recent years, many scholars have observed the fog variations for years, and discussed the relationship between the tempo-spatial distribution of local fog and meteorological factors $[7,8]$. The formation of fog is largely affected by factors such as the annual average temperature, relative humidity, depression of the dew point, low-level horizontal wind, atmospheric stability, vertical wind shear and the temperature 
inversion near the surface layer [9-11]. Fog days are significantly variable both spatially and temporally, and fog may occur frequently or never in a given year. For studying the climatological characteristics of fog in different regions, the annual or monthly average of fog days is mostly analyzed. Many scholars have researched a lot on the frequency of fog days and its weather background, such as the impact of East Asian winter monsoon on haze days and the impact of ENSO on the number of winter fog days in eastern China [12-15].

Arctic Oscillation (AO) was put forward by Thompson and Wallace in 2001 [16]. They pointed out that $\mathrm{AO}$ is the first mode of empirical orthogonal function (EOF) analysis obtained from the sea level pressure in the northern hemisphere, which contributes a large part of the variance of the variability in the northern hemisphere [17]. Further researches also show that the AO anomaly has an important impact on the wintertime climate in East Asia [18-28]. When AO is in the positive phase, the low pressure system in the Arctic region decreases, and the high pressure system in the middle latitudes strengthens, preventing the cold air in the polar region from intruding into the middle latitude region. In this way, the polar pressure is lower than the climatology, and the high pressure in the middle latitude region around the polar region is higher than normal, which strengthens the pressure gradient force pointing to the polar region. Therefore, the cold air mass is not likely to move southward and bring low temperature weather such as cold waves, thus the temperature in the middle and high latitudes of Eurasia is relatively high. When AO is in the negative phase, the pressure is relatively higher in the Arctic polar region, while lower in the middle latitude region around the polar region. As the pressure gradient force pointing to the polar region decreases, resulting in more southward movement of cold air mass and more low temperature weather such as cold waves and gales in the middle and low latitudes.

Based on the observation data of fog days and the reanalysis data, the effect of $\mathrm{AO}$ on the wintertime fog days in east China is discussed in this paper. In order to better distinguish the non-linear characteristics of $\mathrm{AO}$, the number of fog days in the positive and negative phases of $\mathrm{AO}$, the atmospheric circulation, the water vapor distribution and the thermal structure are discussed to find out their relationships with fog days and to provide a basis for the short-term prediction of fog. In addition, as haze is more impacted by pollutant emissions than by meteorological conditions, it is not researched in this paper.

\section{Data and Methods}

\subsection{Data}

The National Centers for Environmental Prediction/National Center for Atmospheric Research (NCEP/NCAR) monthly reanalysis data was used in this paper, including wind fields, geopotential height fields, specific humidity fields, relative humidity fields and temperature fields. The dew point temperature could be calculated based on relative humidity and the temperature, and then the depression of the dew point could be calculated based on the temperature and the dew point temperature. The globe data was from 1954 to 2007 , with a spatial resolution of $2.5^{\circ} \times 2.5^{\circ}$. The number of fog days was observed at 503 weather stations. The monthly data after interpolation with a spatial resolution of $1^{\circ} \times 1^{\circ}$ was adopted. December, January and February were selected as wintertime for 53 years of 1954-2007. To highlight the characteristics of fog days in eastern China, the mapping range of fog days was set as $\left(70-140^{\circ} \mathrm{E}, 15-55^{\circ} \mathrm{N}\right)$. Fog refers to the visible aggregate of a large number of fine water droplets (or ice crystals) suspended near the ground in the atmosphere, causing the atmospheric effective visibility less than $1000 \mathrm{~m}$. Moreover, according to the visibility level, it can be divided into heavy fog (the horizontal visibility is within $0-500 \mathrm{~m}$ ) and light fog (the visibility range is within 500-1000 m). 


\subsection{Methods}

In this paper, the composite analysis method was used to explore the climate background during years with more winter fog days, as well as that during years with less winter fog days. Moreover, the influence of $\mathrm{AO}$ on the background field of meteorological conditions (circulation fields, temperature fields, water vapor fields, etc.), which are conducive to the fog formation was also analyzed in this paper.

Figure 1 shows the time series of $\mathrm{AO}$ in winters of many years. In order to study the effect of $\mathrm{AO}$ on fog days, we defined larger than +0.8 as the positive-phase year of $\mathrm{AO}$ and less than -0.8 as the negative-phase year, with a total of 11 and 12 years (Table 1), respectively. The fog days and the physical quantities of atmospheric circulations in positive and negative anomalous years were respectively composited, and then the influence of $\mathrm{AO}$ on the fog days in eastern China was analyzed. Of course, the AO index had an obvious interdecadal variation. After removing the interdecadal signal of $\mathrm{AO}$, there were 2 different years of $11 \mathrm{AO}$ positive-phase years and 3 different years of $12 \mathrm{AO}$ negative-phase years. However, these different selected years had little impact on our composite results. The geographic locations were described as follows. Eastern China is in $\left(110-120^{\circ} \mathrm{E}, 20-40^{\circ} \mathrm{N}\right)$; North China is in $\left(110-120^{\circ} \mathrm{E}, 30-40^{\circ} \mathrm{N}\right)$; South China is in $\left(110-120^{\circ} \mathrm{E}, 20-30^{\circ} \mathrm{N}\right)$ and the Yangtze River Basin is around $30^{\circ} \mathrm{N}$.

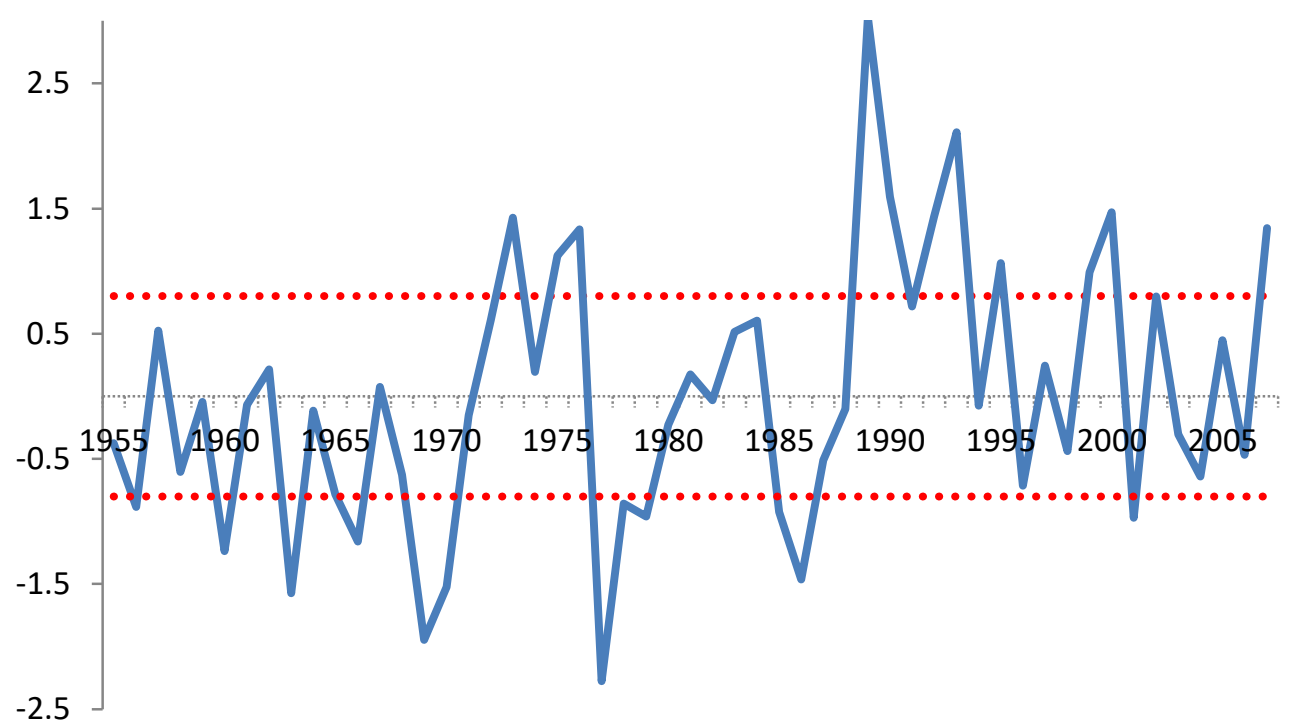

Figure 1. Artic Oscillation (AO) wintertime index during 1954-2007. https://www.cpc.ncep.noaa.gov/ products/precip/Cwlink/daily_ao_index/ao.shtml.

Table 1. Classification of anomalous years based on the phases of wintertime AO index during 1954-2007.

\begin{tabular}{ll}
\hline Positive AO & Negative AO \\
\hline $1972 / 1973,1974 / 1975,1975 / 1976$, & $1955 / 1956,1959 / 1960,1962 / 1963$, \\
\hline $1988 / 1989,1989 / 1990,1991 / 1992$, & $1965 / 1966,1968 / 1969,1969 / 1970$, \\
\hline $1992 / 1993,1994 / 1995,1998 / 1999$, & $1976 / 1977,1977 / 1978,1978 / 1979$, \\
\hline $1999 / 2000,2006 / 2007$ & $1984 / 1985,1985 / 1986,2000 / 2001$ \\
\hline
\end{tabular}

\section{The Distribution of Winter Fog Days in Eastern China and Its Relationship with AO}

\subsection{Climatological Characteristics of Fog Days in Eastern China}

The climatological distribution of winter fog days in eastern China is shown in Figure 2. The numbers of fog days varied greatly in different regions, the number was large in Southeast China while small in Northwest China. The number of heavy fog days in winter (Figure 2a) was more 
than 6 days in most areas of Southeast China. Especially in the Yangtze River Basin, it could exceed 12 days, and also it could exceed 15 days in Sichuan and some coastal areas of Southeast China. The numbers of light fog days in most areas (Figure 2b) were over 20 days, it could exceed 40 and 60 days respectively in the Yangtze River Basin and the Sichuan area. By comparing the climatology of heavy fog and light fog, it could be found that fog days frequently occurred in eastern China and the Yangtze River Basin, especially the Sichuan Province where heavy fog and light fog occurred most frequently due to the topography. However, in the Yangtze River Basin, the large-value areas of heavy fog days were concentrated, while those of light fog days were scattered. Figure $2 \mathrm{c}$, d shows some seasonal cycle characteristics of light fog and heavy fog. The winter heavy fog accounted for more than $30 \%$ of the annual average in eastern China, and $40 \%$ in some areas (Figure 2c). The winter light fog accounted for more than $20 \%$ of the annual average in eastern China, and 30\% in South China (Figure 2d). It shows that light fog was less affected by the seasonal cycle than heavy fog.
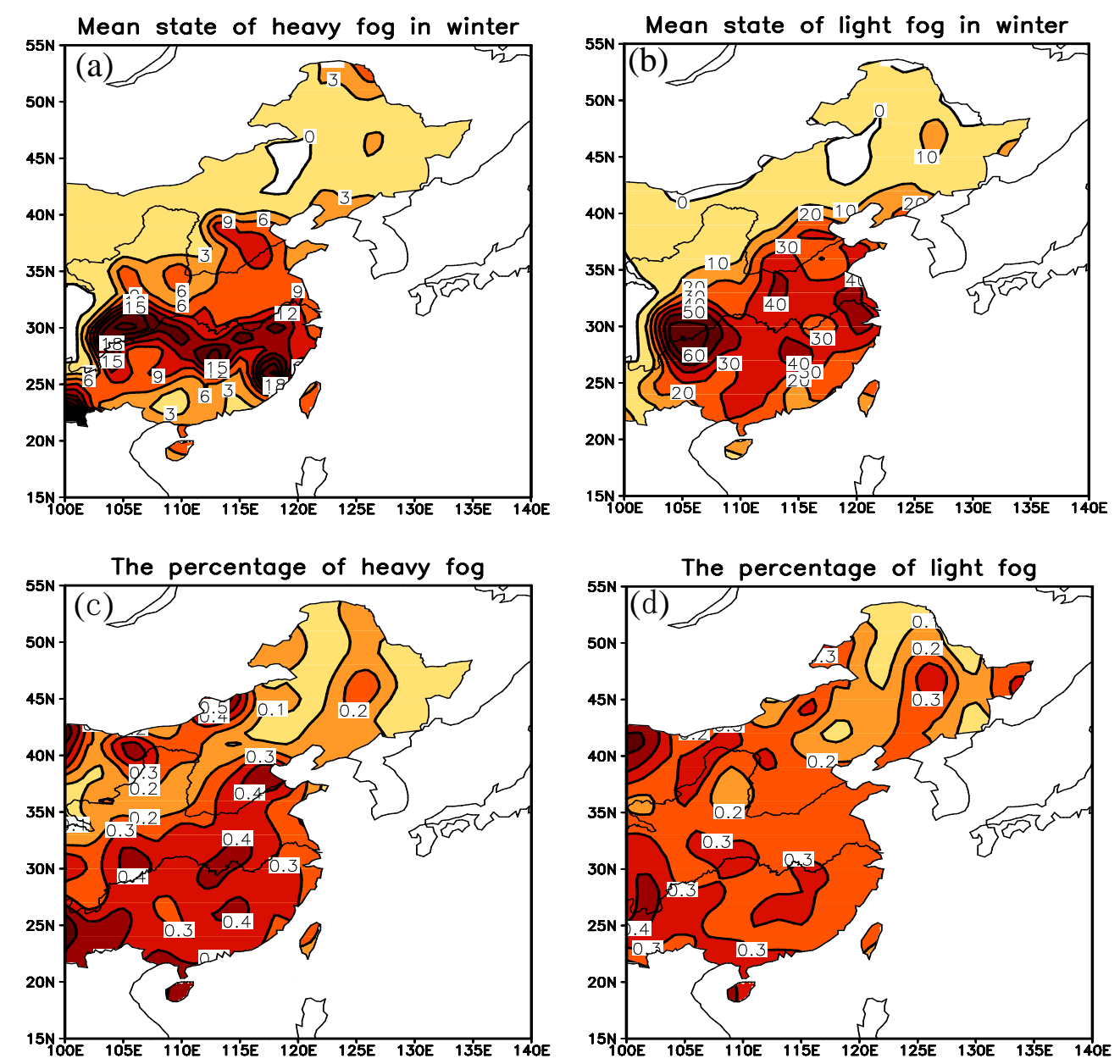

Figure 2. Climatology of winter fog days in east China during 1954-2007, respectively for (a) heavy fog and (b) light fog (unit: day). The ratio of winter fog days on the annual average with (c) heavy fog and (d) light fog.

The annual distribution of standard deviation of winter fog days (Figure 3) reflected the interannual activity of a winter fog day in the recent 50 years. By comparing Figures $2 \mathrm{a}$ and $3 \mathrm{a}$, it was found that the large-value area of the standard deviation of winter heavy fog day resembled the climatology, and it concentrated in Sichuan, the Yangtze River Basin, South China and North China, with the maximum center value of more than 6 days. It indicates that the above areas in winter were the areas with both frequent heavy fog and obvious interannual variation. By comparing Figures $2 b$ and $3 b$ for light fog days, it was found that the large value center of the standard deviation was more south, mainly in the 
coastal area of Southeast China, with the maximum value over 16 days. It might be closely related to the influence of warm and humid air flow on light fog in South China. Overall, the difference of standard deviation between heavy fog days and light fog days was significant.
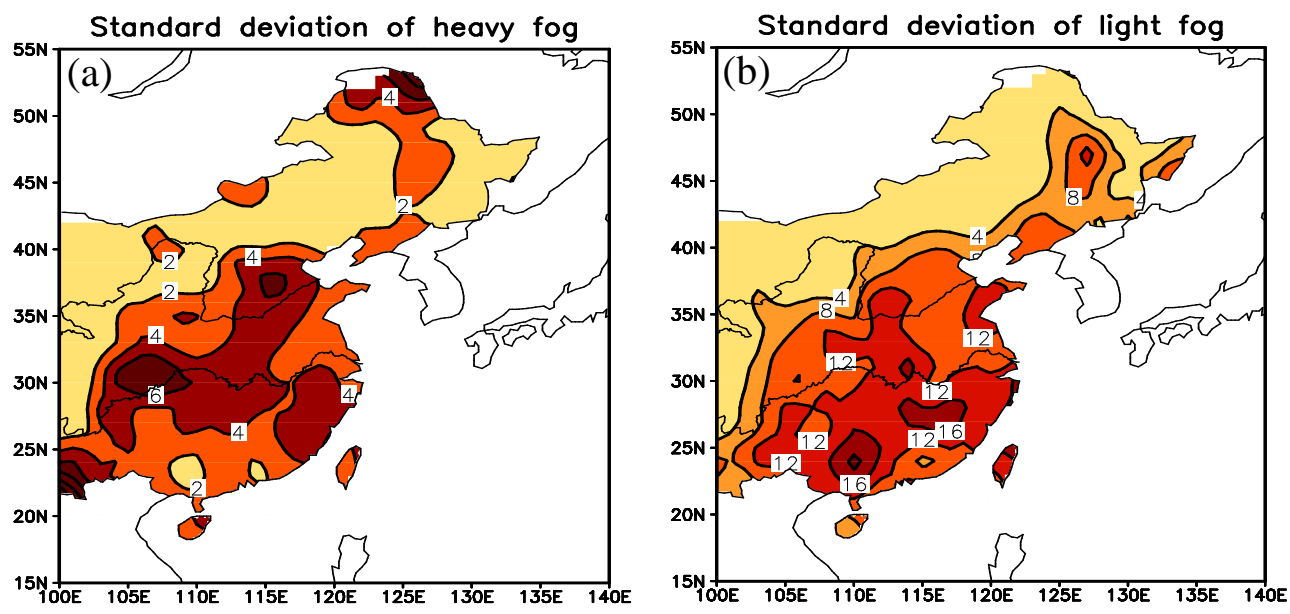

Figure 3. Standard deviation of winter fog days in eastern China during 1954-2007, respectively for (a) heavy fog and (b) light fog (unit: day).

\subsection{Distribution Characteristics of Winter Fog Days with Anomalies of the AO Index}

Based on the winter fog days from the meteorological observation data during 1954-2007 and according to the years of strong $\mathrm{AO}$ and weak $\mathrm{AO}$, the light fog days and heavy fog days during the strong- and weak-AO years in eastern China were composited, respectively, and the anomaly distribution is shown in Figure 4. During strong-AO years, the area corresponding to large and positive anomalies for heavy fog days was located in North China, and the negative one was in South China (Figure 4a). While for light fog days (Figure $4 b$ ), the positive anomalies occupied eastern China, and the center of positive anomaly appeared south of the Yangtze River, reaching more than 9 days. The anomalies of heavy fog days and light fog days south of the Yangtze River were opposite. In the weak-AO year, the heavy fog days south and north of the Yangtze River were a positive anomaly and negative anomaly, respectively (Figure 4c). However, the negative anomaly of light fog days (Figure 4d) was mainly located in east China. There was a significant positive correlation relationship between fog days and AO intensity. The negative anomalies of heavy fog days and light fog days both were located in North China, while south of the Yangtze River, the anomalies of the two were still opposite.

By comparing the anomalies of heavy fog days and light fog days, it was found that the heavy fog days in North China and the light fog days in eastern China both had a positive correlation relationship with $\mathrm{AO}$, while the heavy fog days in South China and $\mathrm{AO}$ had a negative correlation relationship. By comparing the anomalies fog days of strong $\mathrm{AO}$ and weak $\mathrm{AO}$ years, the increase value of both North China heavy fog and light fog in strong $\mathrm{AO}$ years was greater than the decrease value in weak $\mathrm{AO}$ years. The decrease value of South China heavy fog in strong AO years was less than the increase value in weak AO years. These show the asymmetrical effect of $\mathrm{AO}$ on fog days. The physical reason was the key point to further discuss in the following sections. 

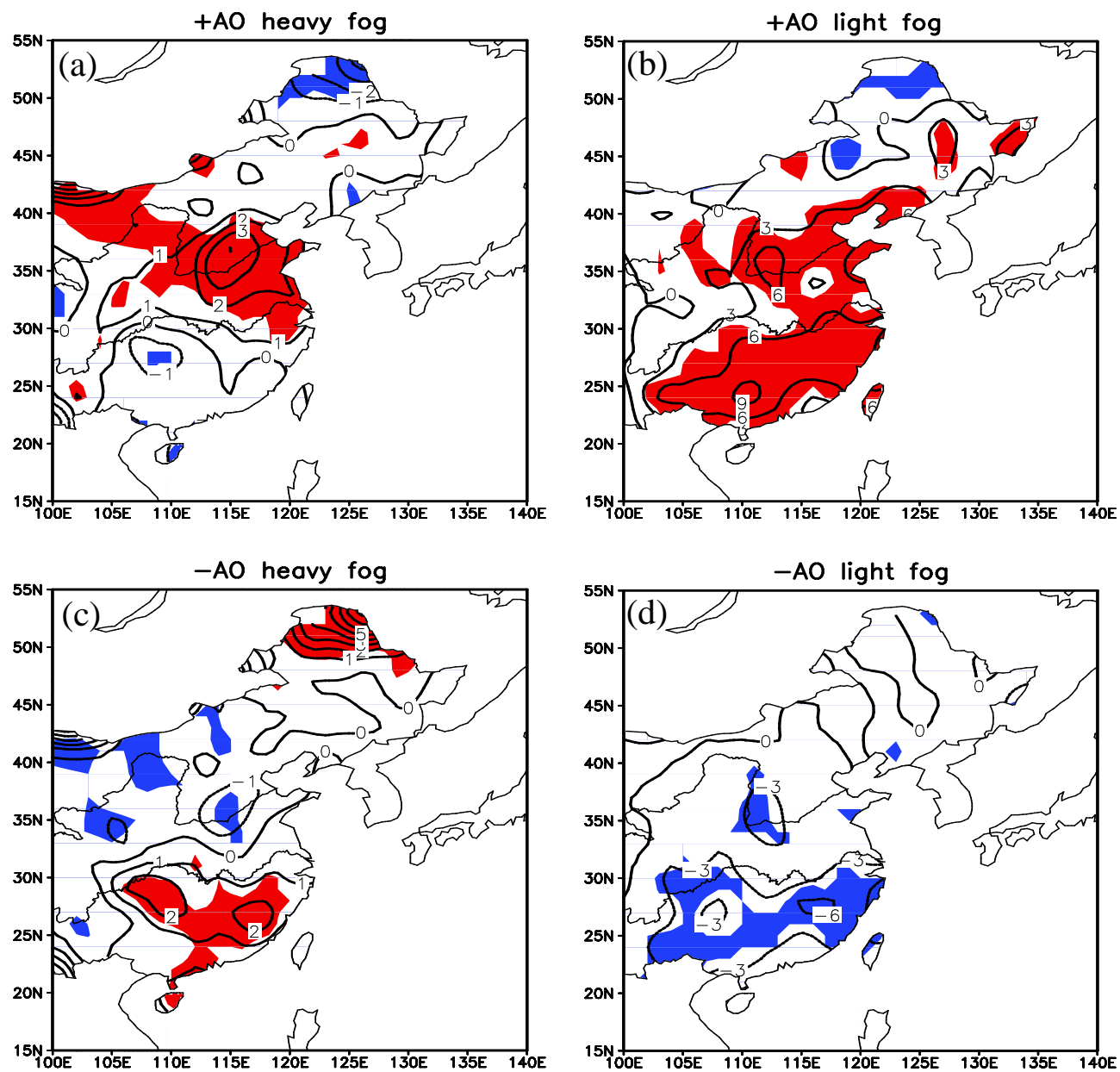

Figure 4. Anomaly of winter fog days in eastern China with positive and negative anomalies of the $\mathrm{AO}$ index. (a) + AO heavy fog, (b) + AO light fog, (c) - AO heavy fog and (d) - AO light fog (unit: day). Shading represents the values above the $90 \%$ confidence level.

\section{The Impact of Winter AO on Atmospheric Circulations and Its Relationship with Fog Days}

\subsection{Air Temperature and Specific Humidity Anomalies with Anomalies of the AO Index}

The occurrence of fog events is mainly related to dynamic and thermal factors. The dynamic factors mainly include the low-level wind field in the atmosphere, the vertical velocity in the middle and lower troposphere, etc. While the atmospheric thermal factors include the temperature $(\mathrm{T})$, specific humidity (q), depression of dew point (T-Td), etc., thus the distributions of temperature, water vapor, geopotential height (Hgt) and wind field in negative- and positive-phase years of AO were analyzed, respectively.

The temperature anomaly at $850 \mathrm{hPa}$ in the positive-phase years of winter $\mathrm{AO}$ is shown in Figure 5a. The warm center was located north of Lake Baikal, with warming anomalies in eastern China weakening from north to south (passing the $90 \%$ significance test). In the negative-phase year of AO (Figure 5b), the cold center of the temperature anomaly was located north of Lake Baikal, which was in good correspondence with the warm center of the temperature anomaly in Figure 5a. The cold anomalies in eastern China and North China extended to the south of the Yangtze River and changed into warm anomalies, but they failed in passing the $90 \%$ significance test. Figure 6 gives the humidity anomaly at $850 \mathrm{hPa}$ in the positive-phase years of winter AO. A significant positive anomaly of water vapor in eastern China provided a proper condition for the occurrence of fog events. The anomaly of water vapor in North China had passed the significance test, and the water vapor anomaly south of 
the Yangtze River was stronger. In the negative-phase year of $\mathrm{AO}$, there was a negative anomaly of water vapor north of $30^{\circ} \mathrm{N}$, which is not conducive to the occurrence of fog. The large-value center was located north of Lake Baikal, which corresponds to the temperature anomaly center (Figure 5b). Positive anomaly of water vapor was found in South China, but did not pass the test.

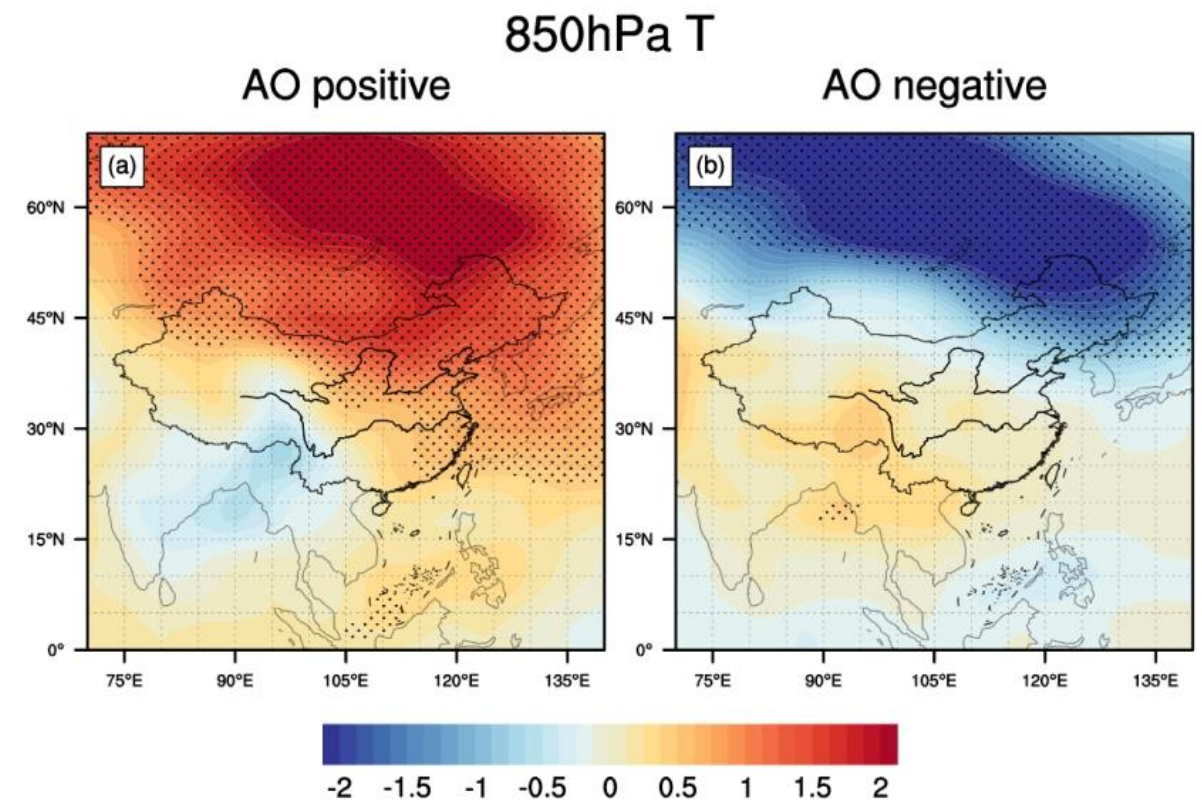

Figure 5. The temperature anomaly at $1000 \mathrm{hPa}$ in winter corresponding to the (a) positive phase and (b) negative phase of AO (unit: K). Dots represent the values above the $90 \%$ confidence level.

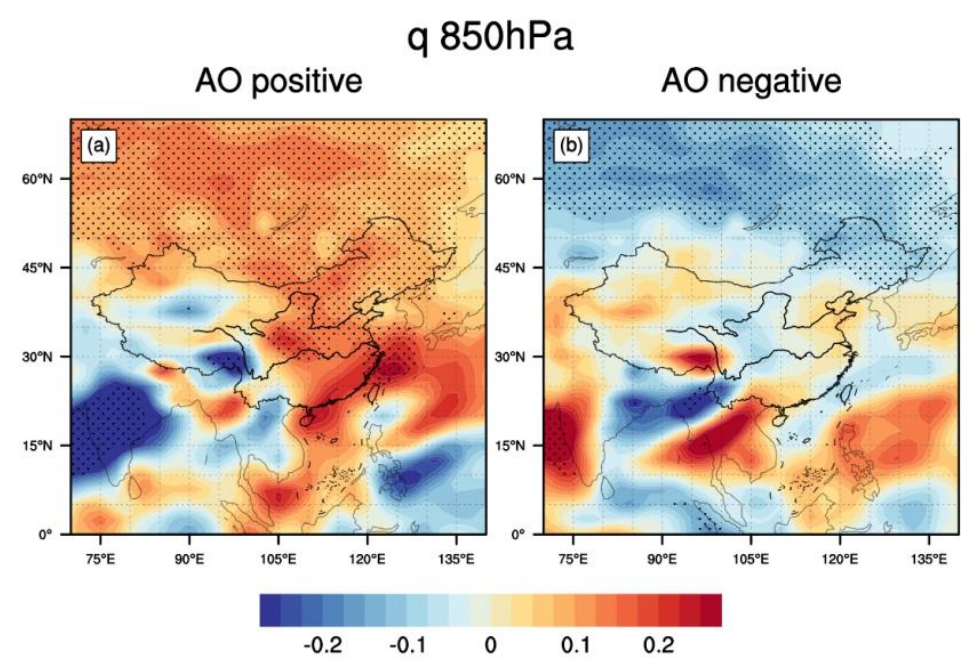

Figure 6. The same as Figure 5, but for the water vapor field at $1000 \mathrm{hPa}$ (unit: $\mathrm{g} / \mathrm{kg}$ ). Dots represent the values above the $90 \%$ confidence level.

\subsection{Geopotential Height, Wind and Rain Anomalies with Anomalies of AO Index}

The East Asian trough is a low-pressure trough formed in the tropospheric westerlies at middle and high latitudes in the northern hemisphere. It is named due to its usual location-on the east coast of the Asian continent and the sea nearby. When the trough line of the East Asian trough is between $105^{\circ}$ $\mathrm{E}$ and $115^{\circ} \mathrm{E}$ and the trough bottom is between $30^{\circ} \mathrm{N}$ and $35^{\circ} \mathrm{N}$ in winter, the deepening of the East Asian trough helps the north cold air move southward, resulting in more frequent cold waves in eastern China. While the shallowing of the East Asian trough is unfavorable for the cold air to move southward, 
increasing the temperature in eastern China. According to the geopotential height field at $500 \mathrm{hPa}$ in the positive-phase year of winter AO (Figure 7a), the polar region corresponded to the negative pressure anomaly, while the North Pacific and eastern China corresponded to positive pressure anomalies, which is the typical structure of positive-phase AO. The positive anomaly of geopotential height was in eastern China, making the East Asian trough weakened and shallower. Then the cold advection was weakened, and the low-level westerly jet moved northward (Figure 8a). The zonal jet can better block the cold air, preventing the cold air from moving southward and helping the southwesterly warm and moisture air move northward. Thus the water vapor gathers in eastern China, and the temperature rises, which is conducive to the formation of large-scale fog. In the negative-phase year of $\mathrm{AO}$, the positive pressure anomaly was located in the polar region (Figure $7 \mathrm{~b}$ ), and the northern China corresponded to the negative pressure anomaly, which shows a typical structure of negative-phase AO. The negative anomaly of the geopotential height in eastern China strengthened and deepened the East Asian trough; the cold advection was active; the low-level westerly jet moved southward (Figure $8 b$ ) and the zonal jet was weaker for blocking the cold air, which was conducive to the cold air moving southward. Therefore, the water vapor and temperature in eastern China were reduced, and the atmosphere became drier, which was not conducive to the formation of large-scale fog.

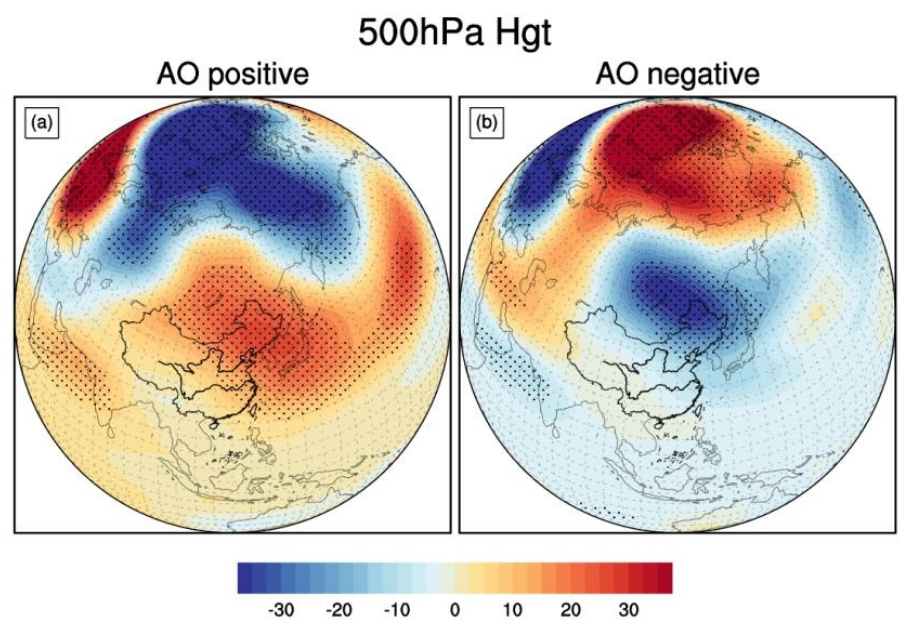

Figure 7. The same as Figure 5, but for the geopotential height field at $500 \mathrm{hPa}$ (unit: gpm). Dots represent the values above the $90 \%$ confidence level.

There was still really poor significant difference of T-Td between AO+ and AO-years (Figure 8), while the significant difference of specific humidity $q$ and temperature T could easily pass the student's $t$-test at the same height according to our computation. However, Td could be significantly influenced by ENSO (Yu et al., 2019) [15], which may infer that ENSO is a strong signal with more anomalous moisture due to SST anomalies, while AO is just a relatively much weaker signal acting smaller impact on moist air abnormally traveling. Therefore, $\mathrm{T}-\mathrm{Td}$ has rational reasons to lack significant differences that cannot pass the student $t$-test, but it can still show its possible contribution to the anomalous patterns of fog days.

To further clarify the impact of AO on fog days, the zonal average of $110-120^{\circ} \mathrm{E}$ was plotted in the latitude-height cross-sections. The distributions of wind field, specific humidity and depression of the dew point with the AO anomalies were discussed. With the positive-phase AO (Figure 9a), the positive anomaly of specific humidity was in the middle and low atmosphere over eastern China, with the maximum value center was in South China (near $23^{\circ} \mathrm{N}$ ) and the maximum value reached $0.15 \mathrm{~g} \mathrm{~kg}^{-1}$. It indicates that there were sufficient water vapor and strong updrafts in the wind field. The negative anomaly of depression of the dew point indicates that it is easy to reach over-saturation. Figure 10a shows that the positive anomaly of heavy rainfall appeared in South China. Although there were more water vapor anomalies in South China, and it was easy to get over-saturated, the 
ascending movement led to the instability of atmospheric stratification, which was not favorable for the occurrence of fog, resulting in less heavy fog days in South China. On the north side of the precipitation anomaly center, the depression of the dew point near $35^{\circ} \mathrm{N}$ shows a negative anomaly, which is likely to get over-saturated, and it is accompanied by downdrafts and a relatively stable atmosphere, thus the fog probably occurs due to the two conditions. Therefore, heavy fog often occurs in North China. The large-scale southwesterly warm and moist air moves northward, which is conducive to both precipitation and light fog.

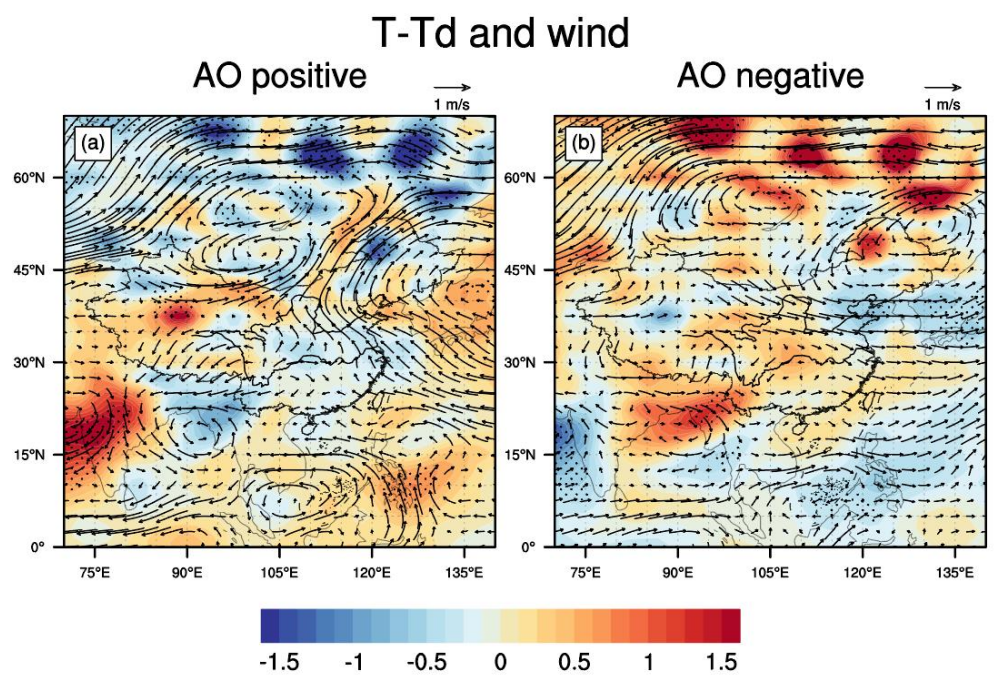

Figure 8. The same as Figure 5, but for the wind and T-Td (shaded) anomaly fields at $850 \mathrm{hPa}$ (unit: $\mathrm{m} / \mathrm{s}$ ). Dots represent the values above the $90 \%$ confidence level.

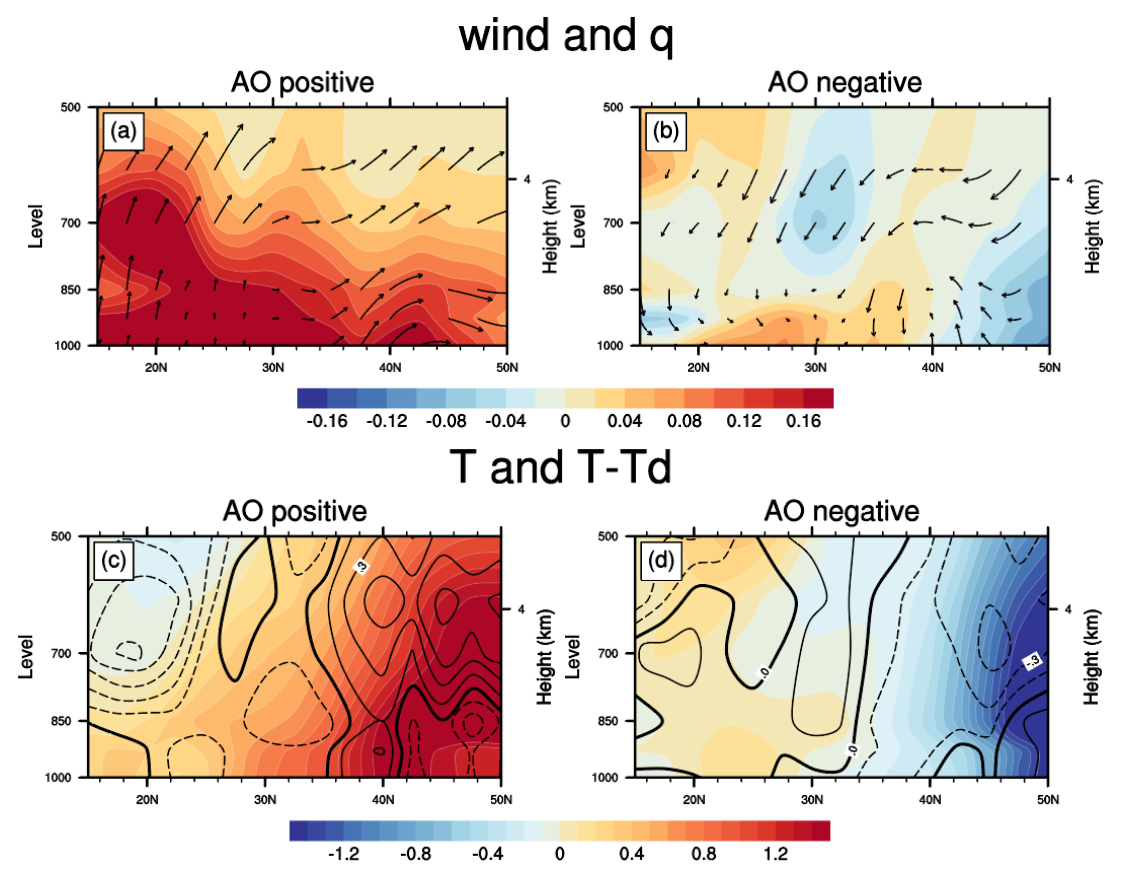

Figure 9. Latitude-height cross-sections of wind (vector), water vapor (shaded) anomaly fields in winter (zonal average of $110-120^{\circ} \mathrm{E}$ ) for the (a) positive $\mathrm{AO}$ and $(\mathbf{b})$ negative $\mathrm{AO}$ (vector, $\mathrm{V}$ unit: $\mathrm{m} \mathrm{s}^{-1}$; $\omega$ unit: $-0.01 \mathrm{~Pa} \mathrm{~s}^{-1}$; specific humidity unit: $\left.\mathrm{g} / \mathrm{kg}\right) .(\mathbf{c}, \mathbf{d})$ are the same as $(\mathbf{a}, \mathbf{b})$, but for the $\mathrm{T}$ (shaded) and $\mathrm{T}-\mathrm{Td}$ (contour) anomaly fields (unit: K). 


\section{Rainfall}

AO positive

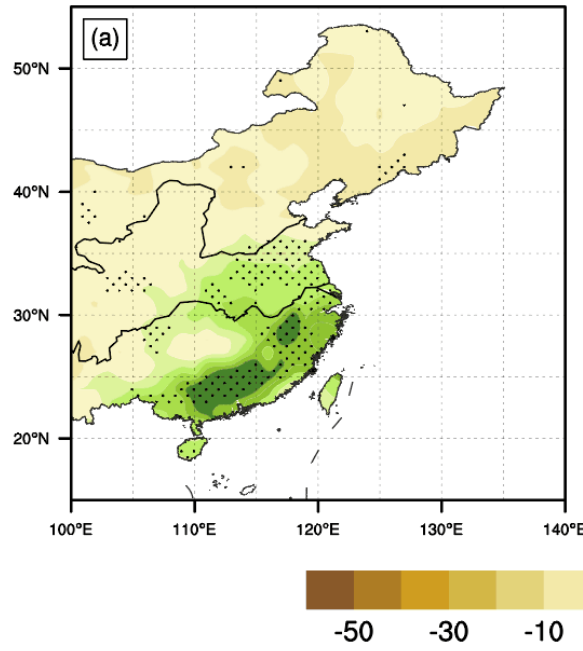

AO negative

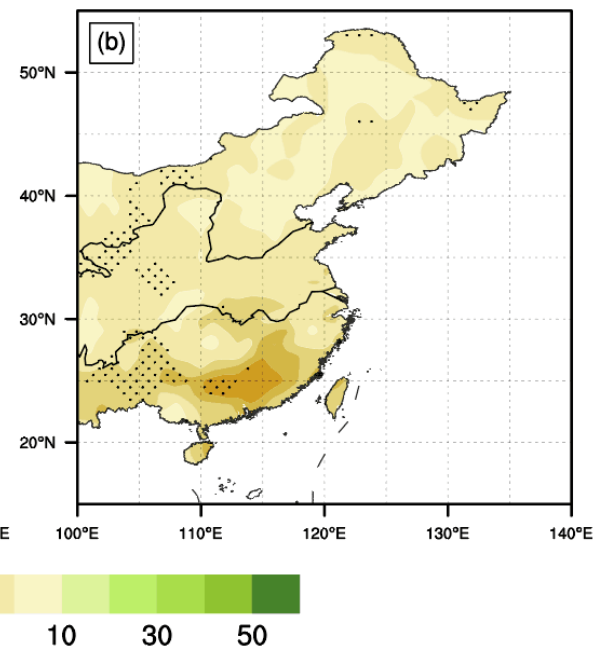

Figure 10. Precipitation anomaly fields in winter for the (a) positive AO and (b) negative AO (unit: $\mathrm{mm}$ ). Dots represent the values above the $90 \%$ confidence level.

With the negative phase of $\mathrm{AO}$ (Figure 9b), water vapor in most areas of eastern China shows the negative anomaly, especially in North China north of $35^{\circ} \mathrm{N}$. Although the depression of the dew point also shows the negative anomaly, which is beneficial to over-saturation, a strong anomalous upward movement appeared at $40^{\circ} \mathrm{N}$. The negative anomaly of water vapor and atmospheric instability lead to the decrease of heavy fog days in North China. The East Asia trough always becomes stronger with a negative AO phase, so the geopotential height would be a little higher on the southwest side of the trough, which makes it much harder for the warm and moist air to proceed northward thus the moisture tends to stagnate there. There was the positive anomaly of water vapor and anomalous downdrafts in South China, and the depression of the dew point shows the insignificant negative anomaly, indicating that the over-saturation was not significant. However, the sufficient water vapor and strong descending were enough to cause more heavy fog days in South China. With the negative phase of AO shown in Figure 10b, obviously a negative anomaly of precipitation appeared in South China, which indicates that the northerly cold air brought dry and cold air, suppressing the precipitation in southern China and reducing the light fog days dependent on water vapor.

\subsection{Relations of Fog Days in Different Regions with AO Index and Regional Meteorological Fields}

The number of fog days is not only influenced by its thermodynamic forming mechanism, but also depends on the large-scale vertical stratification to trigger and preserve the foggy phenomenon. Though some work shows that weak vertical turbulence can contribute to forming fog, from a large-scale and climatological perspective, the primary preconditions are usually under stable conditions with no mean lifting of the air, cooling of moist air near Earth's surface by either radiation or conduction may lead to cloud formation in the form of fog [29]. This mechanism infers that we can use the vertical air velocity to present the atmospheric stability, so we can set our assumption that there will be more fog days without large-scale ascending motion. Moreover, we choose the vertical velocity to represent the atmospheric stability because the former one is easier to build a standing relationship between the meridional velocity because of the Asian monsoon, which is helpful to our research.

It also has to be noted that the large-scale vertical motion is the key point for us to find out the reason to cause different spatial anomalous patterns of heavy fog days and rainfall, for ascending motion is a favorable condition for precipitation but an unfavorable condition for heavy foggy formation. From the above analyses, it was found that the corresponding positive (negative) anomalies of precipitation 
in South China were very obvious in the positive (negative) phase of AO (Figure 10), but the number of fog days in eastern China varied in different regions. For a better discussion on the variation of fog days, the fog days were divided into three types according to different regions-heavy fog in South China, heavy fog in North China and light fog in eastern China (Figure 4).

In addition, comparing with the impact of ENSO (Yu et al., 2019) [15], for there is less influence of humidity by $\mathrm{AO}$, the vertical air velocity seems to play a relatively more important role in causing an anomalous number of fog days. The water vapor in eastern China mainly comes from the southwesterly warm and moist air flow. With the increase of the water vapor between 20 and $30^{\circ} \mathrm{N}$, the southwesterly warm and moist air also strengthens, accompanied by strong ascending motion in South China, thus the precipitation increases. To discuss the relationship of fog days in different regions with water vapor, atmospheric stability and $\mathrm{AO}$, regional water vapor and vertical velocity along $20-30^{\circ} \mathrm{N}$ are selected to correlate with the number of fog days in North China, South China and eastern China, respectively (Figure 11). In order to weaken the effect that fog days are not very significant in South China, South

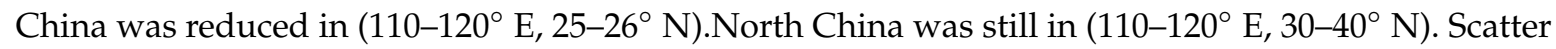
plots (Figure 11a,b) show that the heavy fog days in North China had significant linear correlations with the vertical velocity and specific humidity in South China, indicating that the heavy fog days would actually increase if the warm and moist flow was lifted and proceeded northward. The other two panels (Figure 11c,d) show that the large-scale anomalous downdraft and enhanced moisture led to more heavy fog days in southern China, while the heavy fog days would decrease if the vertical upward motion was too strong. Moreover, there was distinct asymmetry between AO positive and negative phases (Figure 11). For example, a positive AO phase (red) enhanced anomalous amplitudes and gathered points of vertical velocity and specific humidity in South China and the heavy fog days in North China, showing a more stable and definitive impact on them. However, it was the negative AO phase (blue) that led to more steady and significant influence on the heavy fog days in South China, indicating the uncertain and asymmetric impact of $\mathrm{AO}$ on different meteorological variables and the correlations between them.

In order to further explain how the AO index, vertical velocity and specific humidity linearly influence the regional heavy fog, light fog and precipitation, their correlation coefficients were revealed in Table 2. Eastern China was still in (110-120 E, 20-40 N). Through correlation analyses, it was found that the correlation coefficient between the fog days in North China and southwesterly water vapor reached 0.55 , which was the largest. The enhancement of the warm and moist air in South China strengthened the ascending motion in South China, resulting in more precipitation. Although more water vapor increased the precipitation in South China, the anomalous strong ascending was unfavorable for the occurrence of heavy fog. Therefore, the heavy fog days in South China decreased. North of the precipitation center, the anomalous descending motion appeared in North China, and the warm and moist air moved northward, thus heavy fog occurred in North China. The correlation between water vapor and heavy fog in South China was significantly weaker than that in North China, indicating that the strong fog in North China depended on the northward warm and moist air. The relationship between light fog and AO in South China was the closest, with a correlation coefficient of 0.37 . The generation of light fog mainly depended on the warm and wet conditions. When AO was in the positive phase, the warm and moist air from the southwest was likely to move northward, while eastern China was warmer and wetter. Although the updraft in South China was strong, the light fog depending on the warm and wet conditions would occur more frequently. When AO was in the negative phase, the East Asian trough was strong, and the cold air was prone to move southward, thus eastern China was colder and drier. Although the downdraft in South China was strong, the dry and cold air would lead to fewer light fog days. 

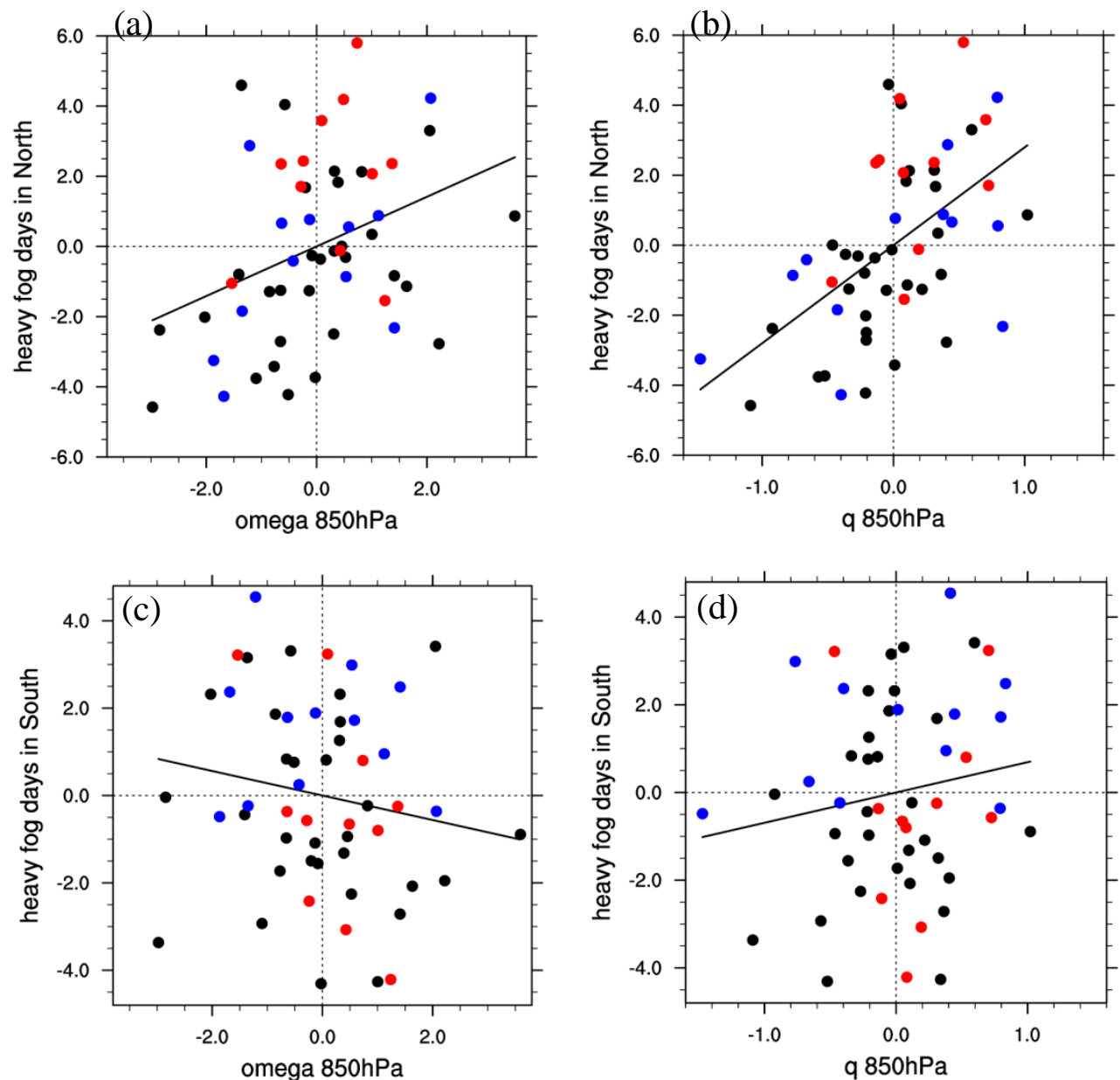

Figure 11. Scatter plots (a) for omega $\left(110-120^{\circ} \mathrm{E}, 20-30^{\circ} \mathrm{N}\right)$ and heavy fog days, (b) for specific humidity $\left(110-120^{\circ} \mathrm{E}, 20-30^{\circ} \mathrm{N}\right)$ and heavy fog days in North China, where the red, blue and black denote the $\mathrm{AO}$ positive phase, $\mathrm{AO}$ negative phase and near neutral states, respectively. The linear fit line is added in each panel. (c,d) in South China are the same as $(\mathbf{a}, \mathbf{b})$ except in North China (omega unit: $-0.01 \mathrm{~Pa} / \mathrm{s}$; specific humidity q unit: $\mathrm{g} / \mathrm{kg}$; heavy fog days unit: day.).

Table 2. Correlation coefficient of fog days in different regions with the AO index and regional meteorological fields (above 0.22 or 0.27 represents the values above the $90 \%$ or $95 \%$ confidence level, respectively).

\begin{tabular}{ccccc}
\hline & $\begin{array}{c}\text { North China } \\
\text { Heavy Fog }\end{array}$ & $\begin{array}{c}\text { South China } \\
\text { Heavy Fog }\end{array}$ & $\begin{array}{c}\text { Eastern China } \\
\text { Light Fog }\end{array}$ & $\begin{array}{c}\text { South China } \\
\text { Precipitation }\end{array}$ \\
\hline AO index & 0.34 & -0.21 & 0.37 & 0.25 \\
vertical velocity $\left(110-120^{\circ} \mathrm{E}, 20-30^{\circ} \mathrm{N}\right)$ & 0.35 & -0.16 & 0.42 & 0.45 \\
water vapor & 0.55 & 0.16 & 0.34 & 0.46 \\
$\left(110-120^{\circ} \mathrm{E}, 20-30^{\circ} \mathrm{N}\right)$ & & & \\
\hline
\end{tabular}

\section{Conclusions and Discussion}

In this paper, based on the winter AO index of 1954-2007, the data of winter fog days in China and the NCEP/NCAR reanalysis data, the climatological distribution characteristics of winter fog days in China were discussed, and the influence of $\mathrm{AO}$ on the number of fog days in eastern China was also studied. The conclusions were as follows.

First, fog frequently occurred in eastern China with strong interannual variability. The larger value of interannual variability and heavy fog mainly concentrated in North China, South China and the Yangtze River Basin, while light fog mainly concentrated in South China. 
Second, when AO was in the positive phase, the polar pressure decreased at the geopotential height of $500 \mathrm{hPa}$; the pressure in East Asia anomalously increased; the East Asia trough decreased; and the low-level westerly jet moved northward, which blocked the northwesterly cold air from moving southward. The temperature and humidity increased in eastern China, and the light fog day increased with more water vapor. The positive phase of $\mathrm{AO}$ was always accompanied by a significantly higher pressure center at the geopotential height of $500 \mathrm{hPa}$ over eastern China and the western Pacific Ocean, around which the large-scale air flowed clockwise. Therefore, there was a significant anomalous southerly flow over eastern China, which blew from the sea in the southeast of China and brought relatively warmer moist air in winter. When such southerly warmer marine air parcels meet the relatively colder air over eastern China, the formal meridional flow tends to build a large-scale ascending motion, because the air parcels with different temperature will interact with each other to lift the warmer one, which is the key thermodynamic mechanism to cause strong anomalous vertical motion during different $\mathrm{AO}$ phases. Due to the increase of warm and humid air flow toward northern China, the precipitation and unstable atmosphere were increased in South China, and the heavy fog days were decreased in South China. The anomalous downdraft on the north side of the precipitation anomaly center was prone to a stable atmosphere. With the increase of water vapor, the heavy fog day in North China also increased.

Third, when $\mathrm{AO}$ was in the negative phase, at a geopotential height of $500 \mathrm{hPa}$, the polar pressure increased; the pressure in East Asia anomalously decreased; the East Asia trough strengthened and the low-level westerly jet moved southward, which was conductive to the southward movement of northwesterly cold air. The temperature and humidity greatly decreased in eastern China, and the light fog day decreased with the water vapor, also the heavy fog day decreased. The East Asia trough always became stronger with the negative AO phase, so the geopotential height would be a little higher on the southwest side of the trough, which makes it much harder for the warm and moist air to proceed northward thus the moisture tends to stagnate there. The anomalous downdraft stable atmosphere and the anomalous increase of water vapor increased heavy fog days in South China.

The heavy fog days in North China obviously increased or decreased in the positive- and negative-phase years of AO, respectively. This phenomenon in South China had a weaker significance than the one in North China. It indicates a significant impact of AO on North China, but a limited impact on South China. South China might be affected more by the tropical factors such as ENSO. For the fog days in the positive- and negative-phase years of $\mathrm{AO}$, the numbers of both heavy fog and light fog days in the positive-phase years were greater than those in the negative-phase years. These show the asymmetrical effect of AO on fog days. In addition, similarly, for the meteorological fields of atmospheric circulations, the intensities and ranges of temperature field, precipitation and geopotential height field in positive-phase years were larger than those in negative-phase years. The above results might be related to the nonlinear effect of $\mathrm{AO}$ on the climate.

$\mathrm{AO}$ can also be affected by ENSO without doubt [30]. AO represents the main signal of the high latitudes and ENSO acts as the one of the tropics. So, the middle latitudes can be influenced by both of them. Therefore, how AO and ENSO jointly affect the number of fog days in eastern China is also worth future study.

Author Contributions: Conceptualization, P.L.; methodology, software, validation, P.L., and M.T.; formal analysis, investigation, data curation, writing —original draft preparation, visualization, P.L.; writing-review and editing, P.L., M.T., H.Y., Y.Z.; resources, supervision, funding acquisition, project administration, H.Y. All authors have read and agreed to the published version of the manuscript.

Funding: This work is jointly supported by National Natural Science Foundation of China under grant 41605045.

Acknowledgments: We thank the four anonymous reviewers for their careful review and insightful comments that lead to an improvement of the study.

Conflicts of Interest: The authors declare no conflict of interest. 


\section{References}

1. Niu, S.J.; Lu, C.S.; Yu, H.Y.; Zhao, L.; Lv, J. Fog research in China: An overview. Adv. Atmos. Sci. 2010, 27, 639-662. [CrossRef]

2. Gultepe, I.; Tardif, R.; Michaelides, S.; Cermak, J.; Bott, A.; Bendix, J.; Muller, M.D.; Pagowski, M.; Hansen, B.; Ellrod, G.; et al. Fog research: A review of past achievements and future perspectives. Pure Appl. Geophys. 2007, 164, 1121-1159. [CrossRef]

3. Yang, D.; Ritchie, H.; Gultepe, I. High-Resolution GEM-LAM Application in marine fog prediction: Evaluation and diagnosis. Weather Forecast. 2010, 25, 727-748. [CrossRef]

4. Gultepe, I.; Kuhn, T.; Pavolonis, M.; Calvert, C.; Gurka, J.; Heymsfield, A.J.; Liu, P.S.K.; Zhou, B.; Ware, R.; Ferrier, B.; et al. Ice fog in Arctic during FRAM-Ice Fog Project: Aviation and nowcasting applications. Bull. Am. Meteor. Soc. 2013, 95, 211-226. [CrossRef]

5. Gultepe, I.; Zhou, B.; Milbrand, J.; Bott, A.; Li, Y.; Heymsfield, A.J.; Ferrier, B.; Ware, R.; Pavolonis, M.; Kuhn, T.; et al. A review on ice fog measurements and modeling. Pure Appl. Geophys. 2014, 169, 765-766. [CrossRef]

6. Gultepe, I.; Heymsfield, A.J.; Gallagher, M.; Ickes, L.; Baumgardner, D. Ice Fog: The Current State of Knowledge and Future Challenges. American Meteorological Society: Meteorological Monographs. 2017. Available online: https://www.research.manchester.ac.uk/portal/en/publications/ice-fog-the-current-state-ofknowledge-and-future-challenges(66a0a9bf-2b65-43d8-8b9b-07af7e269ee9)/export.html\#export (accessed on 25 October 2017).

7. Zhang, R.H.; Li, Q.; Zhang, R.N. Meteorological conditions for the persistent severe fog and haze event over eastern China in January 2013. Sci. China Earth Sci. 2014, 57, 26-35.

8. Zhao, S.; Li, J.; Sun, C. Decadal variability in the occurrence of wintertime haze in central eastern China tied to the Pacific Decadal Oscillation. Sci. Rep.-UK 2016, 6, 27424. [CrossRef]

9. Yin, Z.C.; Wang, H.J.; Guo, W.L. Climatic change features of fog and haze in winter over North China and Huang-Huai Area. Sci. China Earth Sci. 2015, 58, 1370-1376. [CrossRef]

10. Ding, Y.H.; Liu, Y.J. Analysis of long-term variations of fog and haze in China in recent 50 years and their relations with atmospheric humidity. Sci. China Earth Sci. 2014, 57, 36-46. [CrossRef]

11. Ye, H. The influence of air temperature and atmospheric circulation on winter fog frequency over Northern Eurasia. Int. J. Climatol. 2008, 29, 729-734. [CrossRef]

12. Ding, Y.H.; Liu, Y.J.; Liang, S.J.; Ma, X.Q.; Zhang, Y.X.; Si, D.; Liang, P.; Song, Y.F.; Zhang, J. Interdecadal variability of the East Asian winter monsoon and its possible links to global climate change. J. Meteorol. Res. 2014, 28, 693-713. [CrossRef]

13. Li, Q.; Zhang, R.H.; Wang, Y. Interannual variation of the wintertime fog-haze days across central and eastern China and its relation with East Asian winter monsoon. Int. J. Climatol. 2016, 36, 346-354. [CrossRef]

14. Wang, L.; Huang, R.; Gu, L.; Chen, W.; Kang, L.H. Interdecadal variations of the East Asian winter monsoon and their association with quasi-stationary planetary wave activity. J. Clim. 2009, 22, 4860-4872. [CrossRef]

15. Yu, H.; Li, T.; Liu, P. Influence of ENSO on frequency of wintertime fog days in Eastern China. Clim. Dyn. 2019, 52, 5099-5113. [CrossRef]

16. Thompson, D.W.J.; Wallace, J.M. Regional climate impacts of the Northern Hemisphere annular mode. Science 2001, 293, 85-89. [CrossRef]

17. Wallace, J.M.; Gutzler, D.S. Teleconnections in the geopotential height field during the Northern Hemisphere winter. Mon. Weather Rev. 1981, 109, 784-812. [CrossRef]

18. Chen, W.; Zhou, Q. Modulation of the Arctic Oscillation and the East Asian winter climate relationships by the 11-year solar cycle. Adv. Atmos. Sci. 2012, 29, 217-226. [CrossRef]

19. Chen, W.; Lan, X.Q.; Wang, L.; Ma, Y. The combined effects of the ENSO and the Arctic Oscillation on the winter climate anomalies in East Asia. Chin. Sci. Bull. 2013, 58, 1355-1362. [CrossRef]

20. Cohen, J.; Screen, J.A.; Furtado, J.C.; Barlow, M.; Whittleston, D.; Coumou, D.; Francis, J.; Dethloff, K.; Entekhabi, D.; Overland, J.; et al. Recent Arctic amplification and extreme mid-latitude weather. Nat. Geosci. 2014, 7, 627-637. [CrossRef]

21. Gong, D.; Wang, S.; Zhu, J. East Asian winter monsoon and arctic oscillation. Geophys. Res. Lett. 2001, 28, 2073-2076. [CrossRef] 
22. He, S.P.; Wang, H. Linkage between the East Asian January temperature extremes and the preceding Arctic Oscillation. Int. J. Climatol. 2016, 36, 1026-1032. [CrossRef]

23. He, S.P.; Gao, Y.; Li, F.; Wang, H.; He, Y. Impact of Arctic Oscillation on the East Asian climate: A review. Earth Sci. Rev. 2018, 164, 48-62. [CrossRef]

24. Lee, H.S.; Jhun, J.G. Two types of the Asian continental blocking and their relation to the east Asian monsoon during the boreal winter. Geophys. Res. Lett. 2006, 33, L22707. [CrossRef]

25. Li, F.; Wang, H.; Liu, J. The strengthening relationship between Arctic Oscillation and ENSO after the mid-1990s. Int. J. Climatol. 2014, 34, 2515-2521. [CrossRef]

26. Wang, L.; Chen, W. Downward Arctic Oscillation signal associated with moderate weak stratospheric polar vortex and the cold December 2009. Geophys. Res. Lett. 2010, 37, L09707. [CrossRef]

27. Wu, B.; Wang, J. Winter Arctic Oscillation, Siberian High and East Asian winter monsoon. Geophys. Res. Lett. 2002, 29, 1897. [CrossRef]

28. Chen, S.F.; Song, L.Y. Recent Strengthened Impact of the Winter Arctic Oscillation on the Southeast Asian Surface Air Temperature Variation. Atmosphere 2019, 10, 164. [CrossRef]

29. Houze, R.A. Cloud Dynamics, 2nd ed.; Elsevier B.V.: Kidlington, UK, 2014; pp. 101-103.

30. Chen, S.F.; Wu, R.; Chen, W.; Yu, B. Recent weakening of the linkage between the spring Arctic Oscillation and the following winter El Niño-Southern Oscillation. Clim. Dynam. 2020, 54, 53-67. [CrossRef]

(C) 2020 by the authors. Licensee MDPI, Basel, Switzerland. This article is an open access article distributed under the terms and conditions of the Creative Commons Attribution (CC BY) license (http://creativecommons.org/licenses/by/4.0/). 